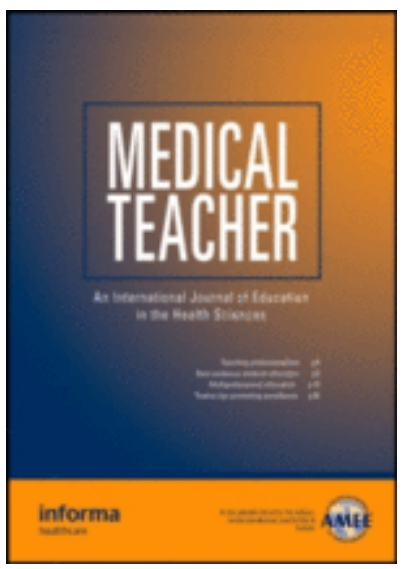

\title{
Progress Testing Anytime and Anywhere - Does a Mobile- Learning Approach Enhance the Utility of a Large-Scale Formative Assessment Tool?
}

\begin{tabular}{|r|l|}
\hline Journal: & Medical Teacher \\
\hline Manuscript ID & CMTE-2019-1642.R1 \\
\hline Manuscript Categories: & Articles \\
\hline Author: & 31 -May-2020 \\
\hline Complete List of Authors: & $\begin{array}{l}\text { Karay, Yassin; University of Cologne, Faculty of Medicine } \\
\text { Reiss, Birger; University of Cologne, Faculty of Medicine } \\
\text { Schauber, Stefan; University of Oslo Faculty of Medicine, Centre for } \\
\text { Health Sciences Education }\end{array}$ \\
\hline Keywords: & $\begin{array}{l}\text { Progress testing < Assessment, Computer-based < Assessment, e- } \\
\text { learning/computers < Teaching \& Learning, Independent < Teaching \& } \\
\text { Learning }\end{array}$ \\
\hline &
\end{tabular}

\section{SCHOLARONE Manuscripts}




\title{
Title
}

Progress Testing Anytime and Anywhere - Does a Mobile-Learning Approach Enhance the Utility of a Large-Scale Formative Assessment Tool?

\author{
Authors \\ Yassin Karay, Dean's Office for Student Affairs, Faculty of Medicine, University of \\ Cologne, Cologne, Germany
}

Birger Reiss, Dean's Office for Student Affairs, Faculty of Medicine, University of Cologne, Cologne, Germany

Stefan K. Schauber, Centre for Health Sciences Education, Faculty of Medicine, University of Oslo, Oslo, Norway

\section{Name, address, telephone and fax number, and email address of corresponding author}

Dr. Yassin Karay

Dean's Office for Student Affairs, Faculty of Medicine, University of Cologne Josef-Stelzmann-Str. 20, Geb. 42

50931 Köln (Germany)

Tel.: $0049-221-47889217$

Fax: $0049-221-47888786$

Email: yassin.karay@uk-koeln.de 


\section{Practice Points}

- We provide evidence that the acceptability among students is increased by a location and time flexible version of the formative progress test.

- Test scores were largely comparable across both groups, while time-on-test was different.

- The examination condition had an effect on student's response behaviour.

- The mobile version of the formative progress test might be related to an increased willingness of many students to take time for the test and to create the best conditions for themselves. 


\section{Abstract}

Background: The widespread use of mobile devices among students favours the use

3 of mobile learning scenarios at universities. In this study, we explore whether a time- and

4 location-independent variant of a formative progress test has an impact on the students'

5 acceptance, its validity and reliability and if there is a difference in response processes

6 between the two exam conditions.

Methods: Students were randomly assigned to two groups of which one took the test

8 free of local or temporal fixations, while the other group took the test at the local testing

9 centre under usual examination conditions. Beside the generated test data, such as test score,

10 time-on-test and semester status, students also evaluated the settings.

11 Results: While there was no significant effect on the test score between the two 12 groups, students in the mobile group spent more time on the test and were more likely to use 13 the help of books or online resources. The results of the evaluation show that the acceptability 14 among students is increased by a mobile version of the formative progress test.

Conclusions: The results suggest that the acceptance and motivation to participate in

16 formative tests is enhanced by lifting local and temporal restrictions. The mobile version 17 nonetheless does not have an impact on the students' performance. 


\section{Introduction}

With the establishment of mobile devices such as smartphones or tablets, time- and location-independent learning (in short: mobile learning) has for years increasingly moved into the focus of all areas of the education system (Zeng and Luyegu 2011). The higher education sector is particularly well suited for mobile learning options, as portable devices are widely used among students (Cheon et al. 2012). Market research predicts that 80 to 90 percent of people in Western Europe will own a smartphone by 2018 (Zenith Mobile Advertising Forecast 2017). In Germany, for instance, the dissemination rate in age groups relevant for universities is 95 to 97 percent (Bitkom Research Statista 2018). The Corona Pandemic 2020 has also made a significant contribution to promoting time- and locationindependent learning at universities. Many universities worldwide had to offer a digital semester for their students within a very short time. Therfeore, it can be assumed that the dissemination rate among students could be increased once again and is almost 100 percent.

The term mobile learning has not yet been defined uniformly. On the one hand, mobile learning is regarded as a part of e-learning (Traxler 2005). On the other hand, mobile learning is seen as an independent learning method (Park et al. 2012). Importantly, a distinct feature of mobile learning is that learners themselves can decide when and where they learn (Peters 2007). Hence, the underlying technology is an enableing factor for offering a more flexible and cost effective - use of learning ressources. Disadvantages might include technical limitations, such as screens that are too small, or slow network speed (Cheon et al. 2012). Further, several authors mention the distraction of the environment or social media applications as a disadvantage (Gikas and Grant 2013). On the other hand, studies show that mobile learning solutions can efficiently support learners in acquiring new knowledge and skills (for an overview see Klímová 2018 and Pimmer et al. 2016). It can therefore make 
sense for university lecturers to rethink conventional learning processes and, if necessary, supplement or even replace them with mobile learning approaches.

Indeed, mobile learning approaches can provide educational institutions the opportunity to broaden the instructional toolkit. For instance, some lecturers routinely use mobile devices to administer quizzes or question students' understanding in a lecture or seminar. In this way, mobile learning platforms can augment the existing instructional approach. Mobile learning approaches might also offer a new, more large-scale way to enhance the utility of specific assessment tools and their role in the educational environment. For instance, mobile solutions might play a critical role when medical schools aim at a tight alignment of instruction, student learning and assessment. The use of a mobile learning device in the context of formative testing might be of particular interest. In the particular context of medical education, a type of assessment that is attracting increasing interest and might benefit form a mobile learning approach is progress testing.

Progress testing has been used as a form of both summative and formative longitudinal assessment since it was first developed in the US in the 1970s (Arnold and Willoughby 1990). A key element of progress testing is its longitudinal character. Hence, a progress test assesses an individual's development of knowledge across his or her course of study. In the Netherlands, Maastricht University was the first to deal intensively with the concept of progress testing (van der Vleuten et al. 1996). Since then, an increasing number of reports mention the use of progress tests in medical schools internationally. In brief, progress testing aims at mitigating usually negative effects of summative assessments (cramming, focusing on isolated topics) by including content from the entire curriculum in each test. Importantly, how often students have to sit a progress test varies between two and four times per academic year. 
One reason for the wide adoption of progress testing may be that medical schools can use such a test to pursue several objectives (Wrigley et al. 2012). Indeed, progress tests tend to maximize the benefits of standardized tests by providing reliable and valid information on students' knowledge, while, at the same time, giving information on the educational environment, useful for curricular planning and improvement. On the downside, however, progress tests are costly: conducting progress tests and maximizing beneficial outcomes is only possible when medical schools invest substantial resources.

In a formative, low-stakes scenario, a major challenge for the beneficial use of progress testing is motivating students to take serious interest and to put effort into the progress test (Schuettpelz-Brauns et al. 2018). Both students and faculty need to invest in taking the test to receive meaningful, valid feedback from it. Hence, one main objective in research on the formative use of progress testing has been to identify the factors that help or hinder students' acceptance of the format. Furthermore, a number of studies have aimed at providing empirical evidence for the validity of formative progress tests.

Previous research has found empirical support for the claim that test scores from formative uses of progress tests provide a meaningful source of information. Karay and Schauber find substantial relations between scores on formative progress tests and grades from high-stakes national licensing examinations, implying that a formative progress test might be used as a prognostic/ forecasting instrument for the performance of cohorts (Karay and Schauber 2018). Further, an earlier study indicated that direct feedback on test results can increase the acceptance of a formative progress test among students (Karay et al. 2012).

In this study, we are interested in the effects of using a mobile learning environment to provide a formative progress test and hence enabling students to take the test at any time and any location. We conducted an experimental study and compared a mobile to a 'standardized' 
89

90

mode of test delivery with respect to a number of critical outcomes. Importantly, van der Vleuten's Utility framework (van der Vleuten 1996) informed our research. In this framework, an assessment's utility can be understood as a combination of the reliability, validity, educational impact, acceptability, and the cost effectiveness. More recent developments, as discussed in (Norcini 2011, Norcini 2018), use a similar perspective to define what a "good assessment" is. Using this framework as a starting point, we address the following research questions:

1.) Does the use of a mobile-testing platform increase student acceptability as opposed to the testing-centre scenario?

2.) Is there a difference in response processes between mobile and standardized testing scenarios?

3.) Do the different testing scenarios affect the progress test's generalizability and reliability?

These questions relate to aforementioned domains of acceptability, validity, and reliability. We address the two remaining factors - educational impact and cost effectiveness - in the discussion of this study's general findings.

\section{Methods}

\section{Educational Context}

The German-language formative progress test is a knowledge test for undergraduate medical students designed at Charité - Universitätsmedizin Berlin. Several German-speaking medical faculties participate in the Berlin Progress Test (BPT). The BPT consists of 200 interdisciplinary MC questions in single-best-answer format. The test covers content from 
112 clinical and para-clinical subjects, as well as from the basic sciences. Every question aims at

113 testing knowledge relevant for a newly certified doctor (Nouns and Georg 2010). As is typical

114 for progress testing, on each occasion all participating students across all semesters answer

115 the same set of items, but items are exchanged between testing occasions. In order to account

116 for the fact that more junior students are not able to answer a large proportion of the

117 questions, there is a "don't know" option that can be used by the test taker. A correct answer

118 is counted as one point while an incorrect answer is marked negatively (deduction of one

119 point); the 'don't know' option does not lead to a point deduction. The test score is then

120 calculated by subtracting the incorrect from the correct answers. Hence, the possible test score

121 ranges from a minimum of -200 to a maximum of 200.

122 The practical integration of the BPT into the existing curriculum varies among 123 cooperating institutions. In Cologne, the BPT is compulsory from the first semester on. In the 124 four-semester pre-clinical study section the BPT must be taken at least three times and in the 125 six-semester clinical study section at least five times (for medical curriculum in Cologne see 126 Zims et al. 2019). Furthermore, the BPT has been carried out computer-based since winter 127 semester 2009/10. At the end of the test, students receive immediate feedback on their test 128 results and are able to compare their answers with the right ones. At the end of the semester, 129 students receive an individual score report prepared by the Charité Medical School. The score 130 report includes information on personal knowledge development in comparison to one's own 131 cohort and detailed feedback on one's own strengths and weaknesses in the different 132 disciplines.

134 Participants and Procedure 
A total of $\mathrm{N}=1,701$ students from semester 2 to semester 10 were randomly assigned

136 to two groups. The first group - the 'mobile' group - was assigned to take their progress test

137 using a mobile learning approach. Students in the mobile group could take the test at any

138 place and any time they deemed appropriate. Furthermore, they were asked to do the test on

139 their own, but there were no controls of whether or not they did adhere to this instruction.

140 Importantly, the only limitations in the mobile group were that students had to complete the

141 test in one single session and within a limited time frame (first twelve weeks of the new

142 semester). In contrast, the second group of students - the testing center group- took the

143 progress test as usual. That is, they were invited on specific dates to the local computerized

144 testing center where they took the test under the same standardized conditions as applied to

145 regular high-stakes exams (i.e., no use of books or other materials, no access to the internet, 146 no use of smartphones etc.).

147 In both conditions, the test was identical with regard to the set of questions used.

148 Furthermore, the progress test and the online questionnaire were delivered using ILIAS

149 software (i.e., an open source learning management system; https://www.ilias.de/en/about-

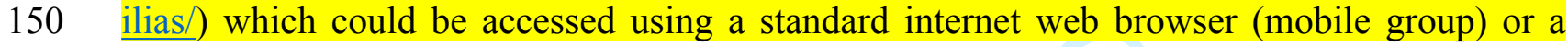
151 secure exam browser (learning centre group). This ensured equal testing platforms, 152 independent of the specific hardware used.

At the end of the semester, about two weeks after the mobile test, the two groups were

154 asked separately about their subjective attitude to their version of the BPT. Students were 155 invited via e-mail to fill out an anonymous online questionnaire that used both comments and 156 scales to rate their experiences. 
Test performance and test-taking behavior. Two objective measures of test-taking

160

161

162

163

164

165

166

167

168

169

170

171

172

173

174 increased acceptance as opposed to the standardized scenario, we analyze differences across

182 the two groups in regard to the self-report questionnaires, the open responses on these

Self-reported motivation and perceived utility. We administered a self-report questionnaire in order to triangulate students' perceptions with the more objective data (score, time). Importantly, in alignment with the local data protection regulations, students were not obliged to answer these forms; data is obtained anonymously and individual responses are not linked to the participants' actual test results. A total number of $\mathrm{N}=9$ questions focused on issues of test-taking behaviour, acceptability and testing conditions. All questions used a rating scale in five categories ranging from "I completely agree" to "I do not agree at all". The open questions were counted with respect to the number of positive and negative comments. We chose a number of typical statements given by the students to illustrate what we deemed to represent a positive or a negative comment.

\section{Analysis}

For testing the first research question, that is, whether the use of mobile-learning 60 
183 questionnaires. When considering differences in responses on the administered 184 questionnaires, we use a generalized linear model to test for differences between groups 185 simultaneously. In a typical regression context, such a group effect would be included as a 186 predictor for some kind of outcome variable. It is, indeed, also possible to include group 187 membership as the outcome variable in a logistic regression. The advantage of this approach 188 in our context is that instead of comparing multiple variables independently of each other, 189 they can be compared simultaneously in one regression model; this avoids issues of multiple 190 comparisons that would be evident when independently testing those variables. Furthermore,

191 we analyze between-group differences in the propensity of individual students being 192 classified as "unmotivated" as opposed to "motivated" test takers by applying a generalized 193 linear model.

The second research question focuses on investigating a possible effect of the different 195 testing conditions on students' response processes. Using a linear mixed model, we address 196 this question by comparing how the time students used on the test (dependent variable) was 197 related to performance (independent variable) and whether there were differences in this 198 respect between the groups. We furthermore test an interaction effect, that is, we account for 199 the possibility that the association between the time used and the performance itself differs 200 between the two groups (performance-group interaction). Using data from the self-reports, we 201 investigate differences between the two groups on variables concerning the response process.

The third question is related to whether the change in the mode of test administration 203 did impact the reliability of the test scores. For this we estimated variance components for the 204 following aspects: students, items, semesters, and their respective interactions as well as the 205 residual variance term. We calculated the relative share of each of the random effects 206 estimated. In addition, we calculated the within-semester reliability coefficients (Cronbach's 207 Alpha) across the two groups. Taken together, we investigate whether there were systematic 
208 differences in the generalizability of the results that were related to the according testing condition.

\section{Results}

\section{Descriptive Statistics}

In both groups, there were about $70 \%$ female participants. Age was comparable with

$214 \mathrm{M}_{(\mathrm{age}, \text { mobile })}=25.3$ years as opposed to $\mathrm{M}_{(\mathrm{age}, \text { testing centre) }}=25.1$ years. Tables $1 \mathrm{a}$ and $1 \mathrm{~b}$ give 215 more detailed descriptive statistics on the key variables included, both for the full dataset and 216 the dataset including only students classified as 'motivated' or 'serious' test takers. In general, 217 students scored better the further they were in their studies. Furthermore, across semesters, 218 students sat the test longer when they were in the mobile group.

For the self-reported motivation and perceived utility questionnaires, complete data for $220 \mathrm{~N}=341$ students was available. The majority of responses was given by students in the 221 mobile group, from which data for $\mathrm{N}_{\text {mobile }}=213$ students were available. A number of 222 students commented on the test using open commentaries, but did not respond to the 223 questionnaires. In the mobile group, $\mathrm{N}=78$ students gave an answer using open commentary; $224 \mathrm{~N}=35$ of such comments were obtained from the testing centre group.

225 Research Question 1: Does the use of a mobile-testing platform increase student 226 acceptance as opposed to the testing-centre scenario?

Differences in evaluation commentaries. As noted above, we tested for differences 228 in evaluation from comments simultaneously by using a generalized linear mixed effects 229 model that included semester as a random effect. Group was entered as the dependent 
230 variable. The items in the questionnaire were predictor variables. In this way, the approach 231 integrates the comparisons across the variables at once, instead of necessitating multiple tests. 232 Figure 1 provides the predictor variables in increasing order, and detailed results for all 233 administered items are found in Table 2. We found that the more strongly students agreed 234 with the question that they could take the progress test under best possible conditions, the 235 more likely they were to be in the mobile-group ( $\mathrm{OR}=18.29$, CI $7.24-46.23, p<.001$ ). 236 Furthermore, students who disagreed more strongly with the counter-factual question that the 237 other condition would have been more motivating were more likely to be in the mobile-group $238(\mathrm{OR}=0.13, \mathrm{CI} 0.05-0.34, p<.001)$.

The open commentaries were categorized into positive, negative and neutral 240 evaluations of the Progress Test. A total of $\mathrm{N}=78$ free text comments were given in the mobile 241 group: of these 73 were positive comments, 1 was negative and 4 were neutral. By contrast, in 242 the testing centre group, 35 comments were given in total. Of these, 21 were positive, 3 were 243 negative and 11 were neutral. In total, there were more positive $(\mathrm{N}=94)$ comments than 244 negative ones $(\mathrm{N}=4)$. A corresponding chi-square test found a statistically significant 245 difference between the number of type of comments given $\left(\chi^{2}=155.55, \mathrm{df}=2, p<0.001\right)$. 246 There was, however, no statistically significant difference between the mobile and the testing 247 centre group concerning this pattern of type of comments $\left(\chi^{2}=5.80, \mathrm{df}=2, p=0.05\right)$.

Differences in likelihood of being classified as a "non-serious" test taker. The 249 results from a generalized mixed effects model including semester as a random effect 250 indicated that the likelihood of 'non-motivated' participation (i.e., only marking the 'don't 251 know' option; handing in the test in a short time while not scoring sufficiently) was 2 times 252 higher in the testing center group than the mobile group $(\mathrm{OR}=2.02$, CI $1.59-2.52, \mathrm{t}=5.71$, $253 \mathrm{p}<.001)$. 
We excluded participants who were classified as 'non-motivated' from further 255 analyses. Hence, in the following analyses, $\mathrm{N}_{\text {mobile }}=544$ students from the 'mobile group' 256 were included as compared to $\mathrm{N}_{\text {testingcenter }}=367$ in the 'testing center' condition (see Tables 1a 257 and $1 b)$.

Research Question 2: Is There a Difference in Response Processes Between Mobile and 259 Standardized Testing Scenarios?

Differences in test-scores across groups. A linear regression model was used to 261 estimate the group effect, the semester and their interaction. We found an effect for semester $262(\beta=10.00$, CI 9.03-10.96, $\mathrm{t}=20.34, \mathrm{p}<.001)$, that is, scores increased as a function of how 263 advanced students were in their studies (standardized $\beta=0.66$ ). Furthermore, neither the 264 group effect $(\beta=-3.81$, CI $-13.18-5.56, \mathrm{t}=-0.80, \mathrm{p}=.426)$ nor the group-semester 265 interaction $(\beta=-0.12, \mathrm{CI}-1.63-1.38, \mathrm{t}=-0.16, \mathrm{p}=.874)$ were statistically significant. We 266 cross-validated the results using a linear mixed effects model and accounting for the different 267 group sizes by including a random effect for semester. Estimates were only marginally 268 affected. In summary, the findings indicate that students that are more senior scored, on 269 average, higher than more junior students (cf. Figure 2). We did not find evidence favoring 270 the interpretation that this relationship could be affected by the mode of administration 271 ('mobile' vs. 'testing center').

Time-on-test differences between groups. Again, a linear model was used to 273 estimate fixed effects for the group effect, the semester and their interaction. In this case, we 274 found a statistically significant effect for both semester $(\beta=3.81$, CI $2.82-4.81, t=7.48$; $275 \mathrm{p}<.001)$ and group $(\beta=-21.16, \mathrm{CI}-30.88--11.44 ; \mathrm{t}=-4.27 ; p<0.001)$. Put differently, the 276 more advanced students were in their studies, the longer they sat the test. In addition, students 
277 in the mobile group sat the test longer than students in the testing centre group. The 278 interaction was not statistically significant $(\beta=-0.68 ; \mathrm{CI}-2.24-0.89 ; \mathrm{t}=-0.85 ; \mathrm{p}=.397)$.

Differences in test-taking behaviour. In the next step, we analysed the data with 280 respect to whether there was a difference between groups in how time-on-test and 281 performance (i.e., correct answers on the progress test) were related to each other. This was 282 done by using a generalized linear mixed model, including semester as a random effect. The 283 number of correct answers was entered as the dependent variable and time, group, and their 284 interaction as fixed effects. The results (Table 3) indicate that time used was positively related 285 to number of correct answers across groups $(\beta=0.71$, CI $0.59-0.82, \mathrm{t}=12.16, \mathrm{p}<.001)$. In 286 addition, students in the testing-centre condition answered more questions per minute 287 correctly as compared to students in the mobile condition, as indicated by a significant time288 group-interaction $(\beta=-0.22,-0.35--0.09, \mathrm{t}=-3.43, \mathrm{p}=.001)$. Finally, there was a non289 significant main effect for the group $(\beta=4.89$, CI $-2.91-12.68, t=1.23, p=0.219)$. The 290 results of this analysis are presented in Figure 3, which illustrates the interaction effect (i.e., 291 non-parallel regression slopes).

292 Results from the analysis of students' responses to the self-report questionnaire align 293 with the findings from the regression model. Students in the mobile group were more likely to 294 agree to the statement that they used help in the form of books or online resources for 295 answering questions in the BPT $(\mathrm{OR}=4.02$, CI $1.61-10.03, p=.003)$.

\section{Research Question 3: Is There a Difference in Score Reliability?}

Again, we used a mixed effects model to estimate variance components. In this analysis, we used data at the level of responses to the particular questions. We included 
300 random effects for Students, Items, Semester and Group in the model. The largest variance 301 component was the residual variance, accounting for $61.20 \%$ of the total variance. Students,

302 Items, Semester, and Group accounted for $9.90 \%, 14.30 \%, 9.60 \%$, and $0.10 \%$, of the total 303 variance, respectively. The only notable interaction was that of Semester and Items, 304 accounting for $4.60 \%$ of the total variance. Detailed results are given in Table 4.

Cronbach's alpha was $\alpha=0.98$ in the mobile group and $\alpha=0.98$ in the testing centre 306 group, across all participating students. Within semesters, Cronbach's alpha varied between 3070.93 and 0.98 in the mobile group and between 0.91 and 0.97 in the testing centre group 308 (Table 5). In summary, the analysis of variance components did not indicate any systematic 309 differences in the group effect. Importantly, estimates of score reliability were largely 310 comparable across the two testing scenarios.

\section{Discussion}

In this study, we investigate whether a time- and location-independent variant of a

313 formative progress test would affect the test's utility using an experimental design. In 314 particular, we focus on questions of acceptability (RQ1), validity (RQ2) and reliability (RQ3).

315 Our results indicate that the acceptability among students is increased by a location- and time316 flexible version of BPT. In the evaluation, both the mobile group and the testing centre group 317 clearly favour the mobile version. The majority of students in the mobile group who 318 responded to the evaluation forms stated that they were able to create the best conditions for 319 processing the BPT by choosing their own time and location. Probably because of the more 320 flexible way to handle the BPT, more students participated in the mobile condition than in the 321 testing centre group.

The possibility to complete the BPT regardless of time and place might be related to 323 an increased willingness of many students to give themselves time to take the test. This might 
324 point at a difference in response processes between the groups. Indeed, compared to the 325 testing centre group, the mobile group reported that they took more time to answer the 326 questions in the best possible way. This statement corresponds to the increased actual time 327 used on the test and the analysis regarding motivated participation. Students from the mobile 328 group worked longer on the test than the other group. Furthermore, they were less likely to 329 quit taking the BPT than students from the testing centre group.

Our analyses indicate that the percentage scores were comparable across groups while time-on-test was different. In a regression analysis, we found that the testing centre students 332 correctly answered more questions per minute than the students in the mobile group. This 333 finding might be explained by the fact that, as students indicated in the self-report 334 questionnaires, they were more likely to use resources to answer questions. Taken together, 335 these findings suggest that the condition had an effect on student's response behaviour. At the 336 same time, scores were largely comparable across both groups.

In view of the increasing competition among universities for financial resources, the 338 consideration of the economic and effective use of scarce resources also plays an important 339 role in teaching. Universities that want to succeed in the face of intensified competition must 340 increase their performance, efficiency and flexibility. Van der Vleutens Utility framework 341 also considers cost efficiency. Compared to the conventional variant of administering the 342 progress test in a testing-centre under exam conditions, the mobile variant of the BPT is 343 significantly more cost-effective. For the mobile variant, for example, there is no need for 344 personnel to supervise the test. Neither is it necessary to provide the rather expensive 345 infrastructure (rooms and computers). In our context, 18 appointments of 3 hours each are 346 typically required to enable all students in the 2 nd to 10 th semesters to take the test. Due to 347 the limited number of computers in the testing centre, a total number of 18 days of testing had 348 to be organized and per day, two to three staff members supervised the test. 
Evidently, shifting to a mobile platform of assessment might change how students and institutions use both the test itself and the test scores. For instance, students in the mobile 351 group might have used the progress test as an opportunity to learn rather than as an actual test

or exam. Indeed, in the mobile group, almost a quarter stated that they had sought help when answering the questions on the test. Still, students have a choice of how to take the test and how to work through the questions, which may be a key factor in using the test in a way that enhances learning. Furthermore, research in cognitive psychology and learning science has long shown that the context in which learning occurs is particularly important for learning (Godden \& Baddeley, 1975; Anderson, Reder \& Simon, 1996; Frankland, Josselyn \& Köhler, 2019). One way of enhancing learning is, according to this strand of research, to diversify the context of learning and assessment. In this way too, students might benefit from not taking the exam under standardized testing conditions.

While we indeed speculate that learning could be enhanced by diversifying assessment contexts, another function of the BPT might be impaired. Since the test is no longer taken under standardized exam conditions, using test scores for benchmarking across institutions is more problematic. However, comparisons are generally limited in this scenario, since the BPT's integration into instructional settings varies across institutions. Therefore, differences and similarities in results can only be compared and discussed against the background of possible influencing factors.

A limitation of the present work is certainly that our study is limited to a single institution. In addition, the mobile testing approach delineated in this study might affect the test's validity and educational impact beyond the effects described. Furthermore, the selfreport questionnaire was composed of statements directly tied to the specific testing scenario here. Its construction was not based on any published or validated framework, but rather motivated by how the test is embedded in the specific context. Hence, we assume that this set 
374 of questions displays a sufficient degree of face validity. Importantly, the general findings 375 from both the analyses of objective measures and the self-report are rather congruent. For this 376 reason, we argue that the two sources complement other and that self-reports critically add the 377 students' perspectives on the intervention discussed here.

Further limitations are related to the deploying tests and other instructional tools on

379 mobile devices, in general. Critics of mobile learning often cite environmental distraction as a 380 disadvantage. In the context of the current study, this point of criticism could not be 381 confirmed from the perspective of students. The students in the mobile group stated that they 382 were less distracted by the environment (e.g. by telephone, other people, etc.) than students in 383 the testing centre group. Students of the mobile-group described that they can create a much 384 quieter working environment for themselves. Some free text comments of the students gives 385 information about the reasons. For example, some students suggested that concentration is not 386 permanently interrupted by fellow students who, for instance, prematurely leave the 387 examination room due to non-serious test-taking.

For the progress test considered here, as much as for other low-stakes testing 389 endeavours, a major challenge is to motivate students to use the test as a valuable feedback 390 tool. Mobile technologies might play a crucial role in offering more flexibility and thus more 391 autonomy in times of crowded schedules and exam dates. Indeed, this might be among the 392 reasons that mobile learning in general is quite popular with medical students. In addition, 393 against the background of increasingly heterogeneous lifestyles of students, universities have 394 to consider the diversity of their students (Karay et al. 2018). In our example this means that 395 commuters, students abroad, working students, and students with children can use the mobile 396 variant to independently determine the optimal time and place for taking the test. Put 397 differently, it is likely not just the 'mobile' nature of the intervention itself that affects the 
399 such as an increase in students' autonomy and flexibility of where, when and how (i.e., using

400 ressources) to take the test. Hence, further research is needed to isolate the specific beneficial 401 apsects of the mobile learning approach. Nevertheless, with the help of flexible teaching and 402 assessment concepts, it is possible to better integrate the students' environment and the 403 educational context - and hence, we argue, to foster learning. 
Anderson, J. R., Lynne M. ., and Herbert A. Simon. Situated learning and education. Educational researcher 25.4 (1996): 5-11.

Arnold L, Willoughby TL 1990. The Quarterly Profile Examination. Acad Med.1990;65(8):515-516.

Bitkom Research, Statista 2018. Available from the Campus License of the University of Cologne: https://de.statista.com/statistik/daten/studie/459963/umfrage/anteil-dersmartphone-nutzer-in-deutschland-nach-altersgruppe/

Zims H, Karay Y, Neugebauer P, Herzig S, Stosch C. 2019. Fifteen years of the cologne medical model study course: has the expectation of increasing student interest in general practice specialization been fulfilled?. GMS Journal for Medical Education 2019, Vol. 36(5), ISSN 2366-5017.

Cheon J, Lee S, Crooks SM, Song, J. 2012. An investigation of mobile learning readiness in higher education based on the theory of planned behavior. Computers in Education, 59(3), 1054-1064.

Frankland, P. W., Josselyn, S. A., \& Köhler, S. (2019). The neurobiological foundation of memory retrieval. Nature neuroscience, 22(10), 1576-1585.

Gikas J, Grant MM. 2013. Mobile Computing Devices in Higher Education. Student Perspectives on Learning with Cellphones, Smartphones and Social Media. The Internet and Higher Education, 19, 18-26.

Godden, D.R., and Baddeley, A.D (1975( Context-dependent memory in two natural environments: On land and underwater. British Journal of psychology 66.3: 325-331.

Karay Y, Hallal H, Stosch C. 2018. Research into finding a stable prognosis parameter for the detection of students in need of guidance - Realization of equal opportunities through a diversity-oriented study guidance. GMS J Med Educ. 2018;35(2):Doc19. DOI: $10.3205 / \mathrm{zma} 001166$.

Karay Y, Schauber SK. 2018: A validity argument for progress testing: Examining the relation between growth trajectories obtained by progress tests and national licensing examinations using a latent growth curve approach, Medical Teacher, DOI: 10.1080/0142159X.2018.1472370.

Karay Y, Schauber SK, Stosch C, Schuettpelz-Brauns K. 2012. Can computer-based assessment enhance the acceptance of formative multiple choice exams? A utility analysis. Medical Teacher 2012;34:292-6.

Klímová B. 2018. Mobile Learning in Medical Education. J Med Syst 42(10):194. doi: 10.1007/s10916-018-1056-9. 
Norcini J, Anderson B, Bollela V, Burch V, Costa MJ, Duvivier R, Galbraith R, Hays R, Kent A, Perrott V, Roberts T. 2011. Criteria for good assessment: Consensus statement and recommendations from the Ottawa 2010 Conference, Medical Teacher, 33:3, 206-214, DOI: 10.3109/0142159X.2011.551559.

Norcini J, Anderson MB, Bollela V, Burch V, Costa MJ, Duvivier R, Hays R, Mackay MFP, Roberts T, Swanson D. 2018. Consensus framework for good assessment, Medical Teacher, 40:11,11021109, DOI: 10.1080/0142159X.2018.150016.

Nouns ZM, Georg W. 2010. Progress testing in German speaking countries, Medical Teacher, 32:6, 467-470, DOI: 10.3109/0142159X.2010.485656.

Nouns Z, Schauber S, Witt C, Kingreen H, Schüttpelz-Brauns K. 2012. Development of knowledge in basic sciences: a comparison of two medical curricula. Medical Education, 46: 1206-1214. doi:10.1111/medu.12047.

Park SY, Nam MW, Cha SB. 2012. University students' behavioural intention to use mobile learning: Evaluating the technology acceptance model. Brit. J. Educ. Technol. 43:592-605.

Peters K. 2007. m-learning: positioning educators for a mobile, connected future. International Review of Research in Open and Distance Learning, 8(2), 1-17.

Pimmer C, Mateescu M, Gröhbiel U. 2016. Mobile and ubiquitous learning in higher education settings. A systematic review of empirical studies. Computers in Human Behavior 63. doi: 10.1016/j.chb.2016.05.057.

Schuettpelz-Brauns K, Kadmon M, Kiessling C, Karay Y, Gestmann M, Kaemmer JE. 2018. Identifying low test-taking effort during low-stakes tests with the new Testtaking Effort Short Scale (TESS) - development and psychometrics. BMC Medical Education 18:101, DOI: 10.1186/s12909-018-1196-0.

Traxler J. 2005. Defining Mobile Learning. Proceedings, IADIS International Conference Mobile Learning 2005, Malta, pp 261-266.

van der Vleuten CP. 1996. The assessment of professional competence: Developments, research and practical implications. Adv Health Sci Educ 1(1):41-67.

van der Vleuten CP, Verwijnen GM, Wijnen WH. 1996. Fifteen years of experience with progress testing in a problem-based learning curriculum. Med Teach. 1996;18:103-109.

Wrigley W, van der Vleuten CP, Freeman A, Muijtjens A. 2012. A systemic framework for the progress test: Strengths, constraints and issues: AMEE Guide No. 71, Medical Teacher, 34:9, 683-697, DOI: 10.3109/0142159X.2012.704437.

Zenith Mobile Advertising Forecast. Press Release Düsseldorf, 16th October 2017: Smartphone penetration to reach $66 \%$ in 2018. Available from: https://www.zenithmedia.com/smartphone-penetration-reach-66-2018/ 
501

502

503
Zeng R, Luyegu E. 2011. Mobile learning in higher education. In Olofsson AD, Lindberg JO (Eds.). Informed design of educational technologies in higher education: Enhanced learning and teaching (pp. 292-306). IGI Global. 


\section{TABLES}

Table 1a: Descriptive statistics for all participants

\begin{tabular}{|c|c|c|c|c|c|c|c|c|}
\hline \multirow[b]{2}{*}{ Semester } & \multicolumn{4}{|c|}{ Mobile Group } & \multicolumn{4}{|c|}{ Testing Centre Group } \\
\hline & $\mathrm{N}$ & $\begin{array}{l}\text { Testscore } \\
\text { (correct- } \\
\text { incorrect) }\end{array}$ & $\begin{array}{c}\text { Number } \\
\text { correct }\end{array}$ & $\begin{array}{l}\text { Time (in } \\
\text { minutes) }\end{array}$ & $\mathrm{N}$ & $\begin{array}{l}\text { Testscore } \\
\text { (correct- } \\
\text { incorrect) }\end{array}$ & $\begin{array}{c}\text { Number } \\
\text { correct }\end{array}$ & $\begin{array}{l}\text { Time (in } \\
\text { minutes) }\end{array}$ \\
\hline 2 & 88 & 11.69 & 22.23 & 57.82 & 76 & 6.88 & 15.68 & 36.3 \\
\hline 3 & 94 & 9.04 & 20.84 & 57.11 & 78 & 6.47 & 16.04 & 31.71 \\
\hline 4 & 58 & 10.57 & 24.05 & 53.71 & 24 & -3.96 & 23.54 & 30.46 \\
\hline 5 & 86 & 27.55 & 40.26 & 66.51 & 80 & 17.73 & 33.45 & 40.18 \\
\hline 6 & 78 & 25.81 & 42.46 & 56.72 & 69 & 15.1 & 27.04 & 33.07 \\
\hline 7 & 94 & 39.53 & 52.34 & 64.97 & 82 & 34.74 & 45.37 & 42.55 \\
\hline 8 & 78 & 43.31 & 59.28 & 74.96 & 73 & 26.97 & 39.53 & 32.88 \\
\hline 9 & 87 & 51.36 & 70.37 & 63.4 & 73 & 37.9 & 52.22 & 39.41 \\
\hline 10 & 56 & 47.54 & 61.09 & 65.21 & 44 & 41.64 & 55.23 & 39.05 \\
\hline Total & 719 & & & & 599 & & & \\
\hline
\end{tabular}

Table 1b: Descriptive statistics for participants classified as 'serious' test takers

\begin{tabular}{|c|c|c|c|c|c|c|c|c|}
\hline \multirow[b]{2}{*}{ Semester } & \multicolumn{4}{|c|}{ Mobile Group } & \multicolumn{3}{|c|}{ sting Centre Group } & \multirow[b]{2}{*}{$\begin{array}{l}\text { Time (in } \\
\text { minutes }\end{array}$} \\
\hline & $\mathrm{N}$ & $\begin{array}{l}\text { Testscore } \\
\text { (correct- } \\
\text { incorrect) }\end{array}$ & $\begin{array}{c}\text { Number } \\
\text { correct }\end{array}$ & $\begin{array}{l}\text { Time (in } \\
\text { minutes) }\end{array}$ & $\mathrm{N}$ & $\begin{array}{l}\text { Testscore } \\
\text { (correct- } \\
\text { incorrect) }\end{array}$ & $\begin{array}{c}\text { Number } \\
\text { correct }\end{array}$ & \\
\hline 2 & 73 & 13.59 & 25.7 & 66.08 & 57 & 10.11 & 18.56 & 42.28 \\
\hline 3 & 74 & 12.7 & 25.23 & 67.45 & 51 & 11.88 & 22.82 & 42.71 \\
\hline 4 & 42 & 16.93 & 31.02 & 70.6 & 13 & 18.69 & 30.46 & 45.69 \\
\hline 5 & 76 & 31.36 & 45.34 & 73.59 & 60 & 28.15 & 40.45 & 49.37 \\
\hline 6 & 57 & 36.46 & 55.79 & 74.09 & 33 & 30.85 & 48.85 & 57.18 \\
\hline 7 & 69 & 52.86 & 68.86 & 82.78 & 54 & 50.52 & 64.67 & 58.61 \\
\hline 8 & 55 & 61.45 & 80.38 & 97.62 & 34 & 55.82 & 75.47 & 61.21 \\
\hline 9 & 60 & 72.92 & 98.63 & 86.82 & 39 & 70.95 & 90.13 & 65.87 \\
\hline 10 & 38 & 69.21 & 88.39 & 93.55 & 26 & 68.27 & 88.42 & 60.19 \\
\hline Total & 544 & & & & 367 & & & \\
\hline
\end{tabular}


Table 2: Generalized linear mixed effects model for the responses to evaluation forms

\begin{tabular}{|c|c|c|c|c|}
\hline Predictors & Odds Ratios & $\mathrm{Cl}$ & Statistic & $p$ \\
\hline (Intercept) & 0.22 & $0.11-0.45$ & -4.17 & $<0.001$ \\
\hline $\begin{array}{l}\text { "I took sufficient time for answering the } \\
\text { questions" }\end{array}$ & 1.09 & $0.57-2.10$ & 0.27 & 0.789 \\
\hline $\begin{array}{l}\text { "I used available resources (books/internet) for } \\
\text { answering the questions" }\end{array}$ & 4.02 & $1.61-10.03$ & 2.98 & 0.003 \\
\hline $\begin{array}{l}\text { "I would like to use old tests for training } \\
\text { purposes" }\end{array}$ & 2.10 & $1.09-4.03$ & 2.23 & 0.026 \\
\hline $\begin{array}{l}\text { "I got interrupted while taking the test (e.g., by } \\
\text { others, telephone calls)" }\end{array}$ & 2.34 & $1.29-4.22$ & 2.81 & 0.005 \\
\hline $\begin{array}{l}\text { "The progress test should be done self- } \\
\text { administered and on a mobile platform" }\end{array}$ & 1.53 & $0.86-2.69$ & 1.46 & 0.145 \\
\hline $\begin{array}{l}\text { "...in addition it should be possible to take the } \\
\text { test under regular exam conditions" }\end{array}$ & 0.77 & $0.43-1.40$ & -0.85 & 0.393 \\
\hline $\begin{array}{l}\text { "The mobile (alternatively: testing center) } \\
\text { condition provided the best opportunity for } \\
\text { creating optimal conditions for working through } \\
\text { the test" }\end{array}$ & 18.29 & $7.24-46.23$ & 6.14 & $<0.001$ \\
\hline $\begin{array}{l}\text { "As a formative test, the progress test should } \\
\text { be used for rehearsing high-stakes testing and } \\
\text { thus be done under summative exam } \\
\text { conditions" }\end{array}$ & 0.50 & $0.31-0.82$ & -2.74 & 0.006 \\
\hline $\begin{array}{l}\text { "It would have been more motivating to do the } \\
\text { test on a mobile platform (in the testing center)" }\end{array}$ & 0.13 & $0.05-0.34$ & -4.19 & $<0.001$ \\
\hline \multicolumn{5}{|l|}{ Random Effects } \\
\hline$\sigma^{2}$ & 3.29 & & & \\
\hline $\mathrm{T}_{00}$ Fachsemester & 0.00 & & & \\
\hline Observations & 341 & & & \\
\hline
\end{tabular}

Note. Questions 7 and 9 were differently phrased for the two groups 
Table 3: Linear mixed effects model for test score on the formative progress test as a function of assigned group and time on the test

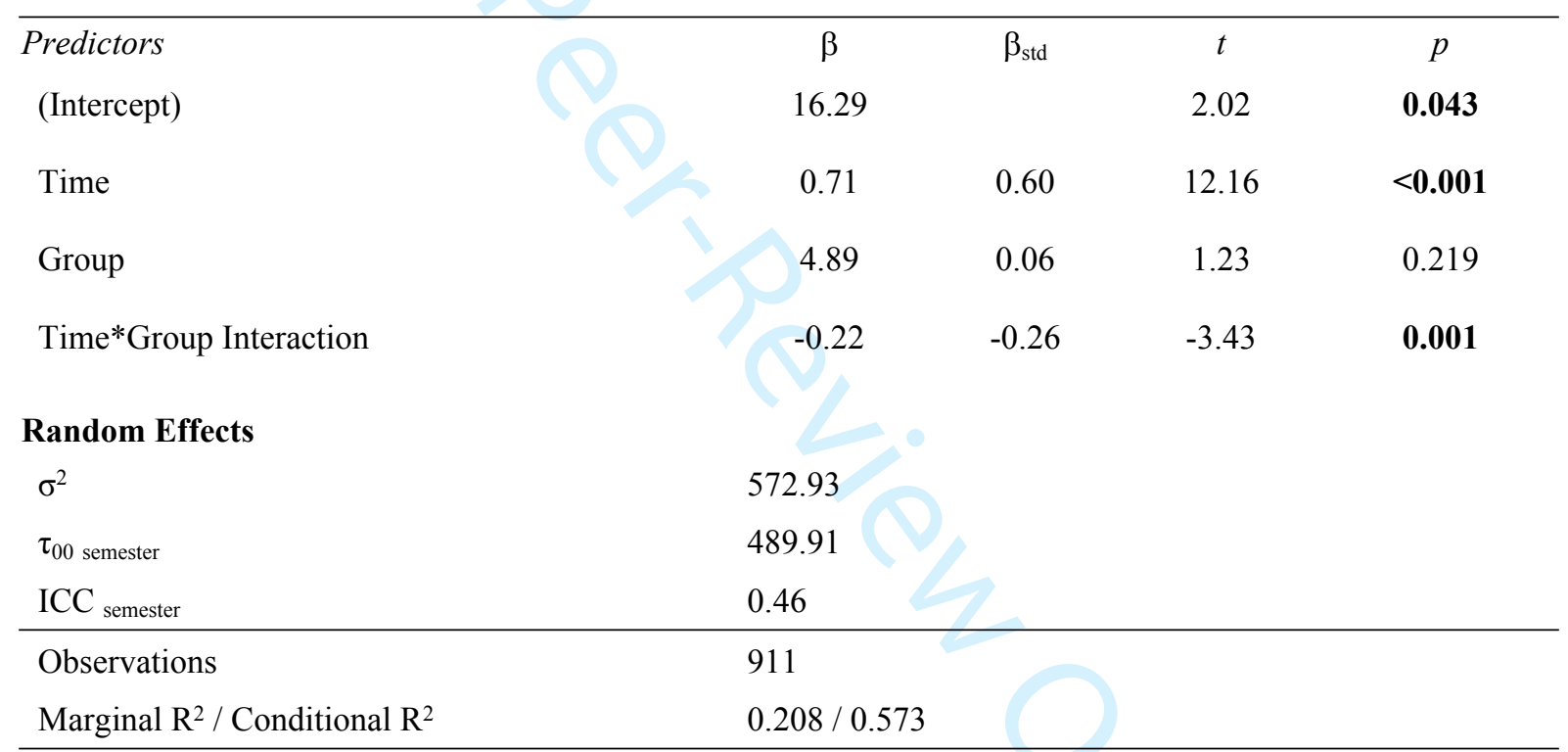

Table 4: Estimates for Variance Components for the Progress Test

\begin{tabular}{lccc}
\hline Variance Component & Observations & Estimate & Relative Share (in Percent) \\
\hline ID & 911 & 1.96 & 9.90 \\
Group & 2 & 0.02 & 0.10 \\
Item & 200 & 2.84 & 14.30 \\
Semester & 9 & 1.89 & 9.60 \\
Group*Item & 400 & 0.01 & 0.00 \\
Group*Semester & 18 & 0.00 & 0.00 \\
Semester*Item & 1800 & 0.91 & 4.60 \\
Semester*Item*Group & 3600 & 0.05 & 0.20 \\
\hline Residual & & 12.11 & 61.20 \\
\hline
\end{tabular}


Table 5: Cronbach's alpha across semesters an groups

\begin{tabular}{ccc}
\hline Semester & Mobile Group & Testing Centre \\
\hline 2 & 0.95 & 0.94 \\
3 & 0.93 & 0.96 \\
4 & 0.97 & 0.91 \\
5 & 0.96 & 0.97 \\
6 & 0.97 & 0.97 \\
7 & 0.97 & 0.96 \\
8 & 0.98 & 0.97 \\
9 & 0.98 & 0.97 \\
10 & 0.98 & 0.97 \\
\hline
\end{tabular}




\section{FIGURES}

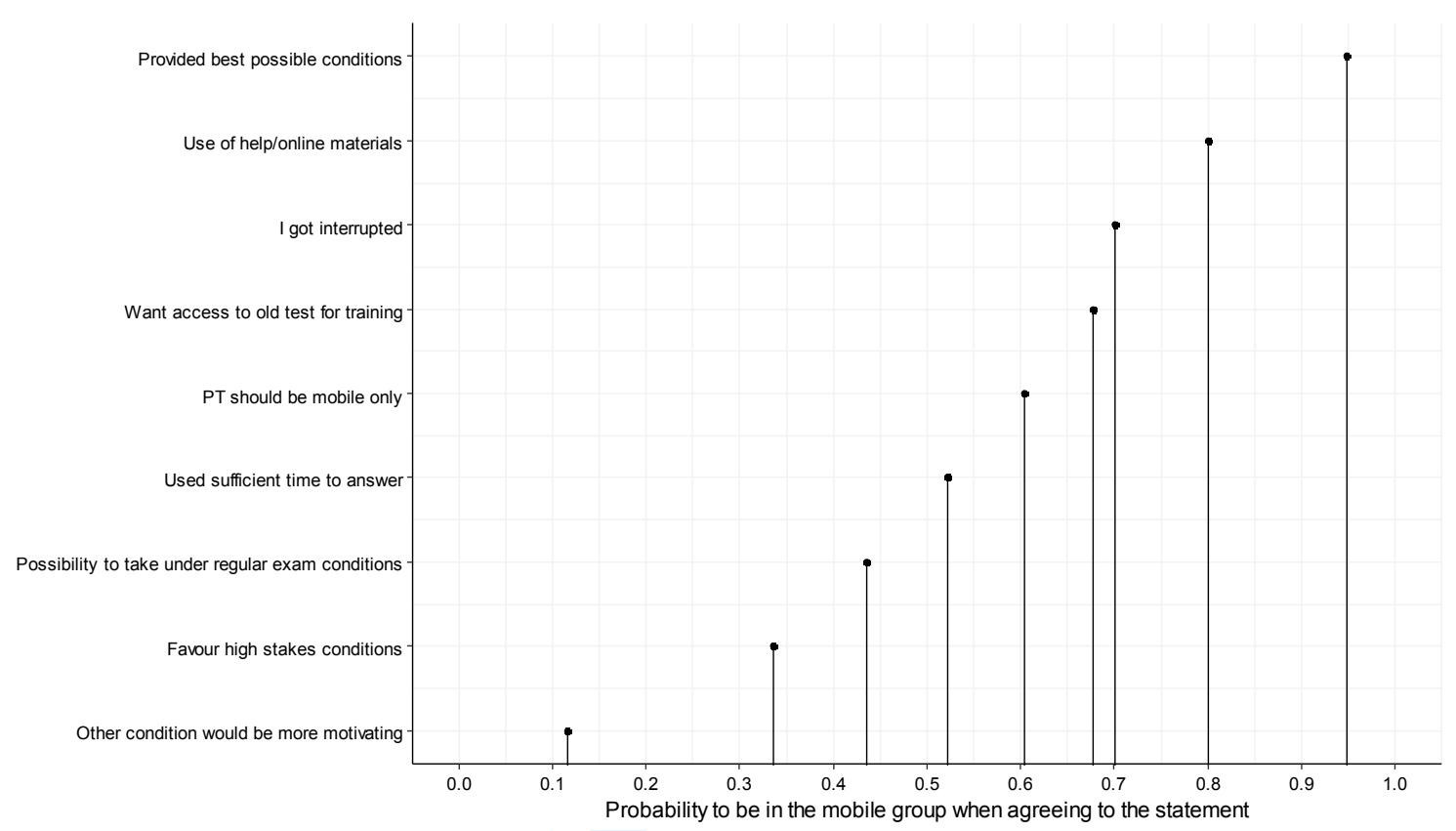

Figure 1. Results from the evaluation questionnaire showing in statements to be endorsed as a function of the condition students were assigned to.

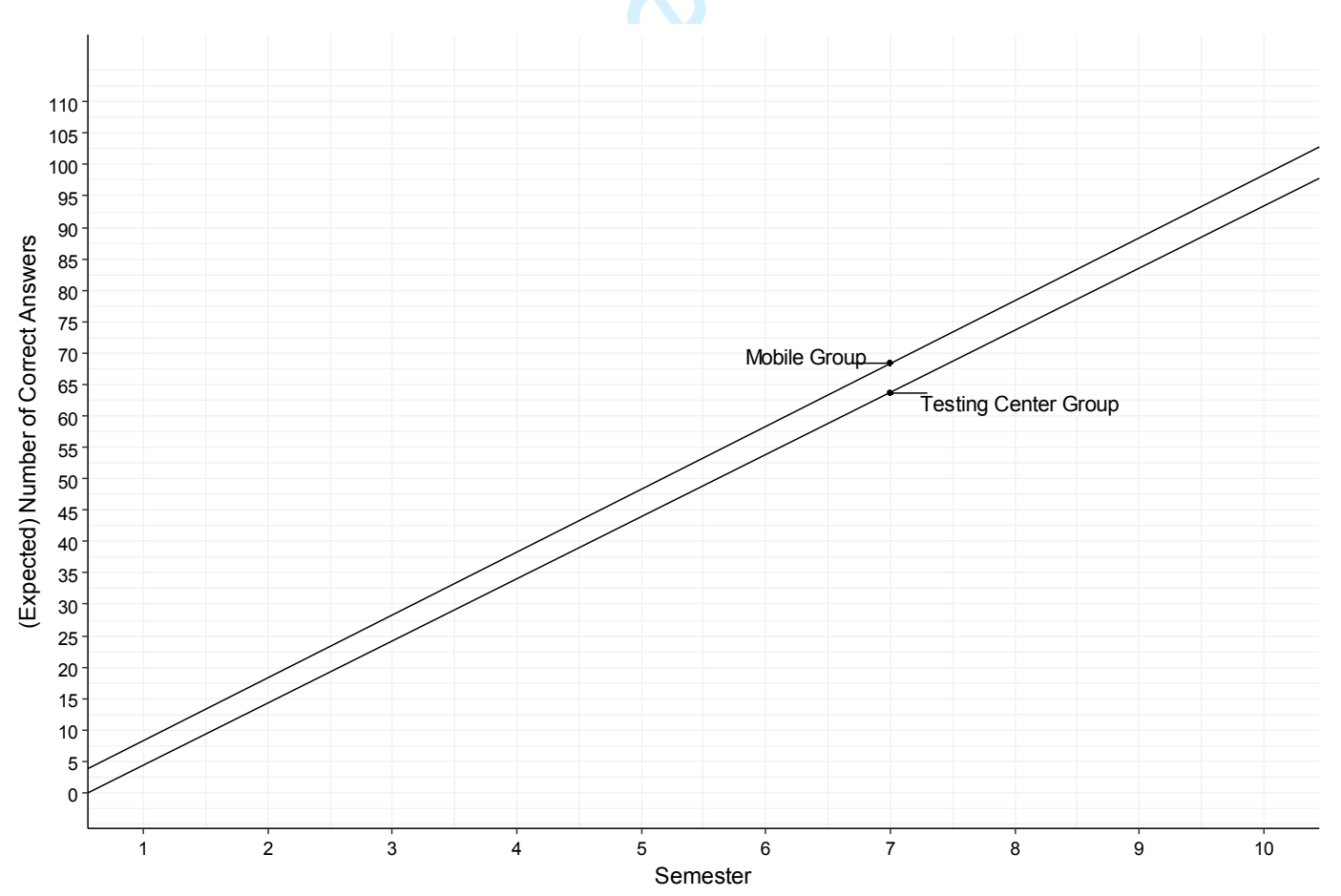

Figure 2. Number of expected correct answers for the two groups across semesters showing generally slightly higher scores for the mobile learning condition (the group effect is not statistically significant) 


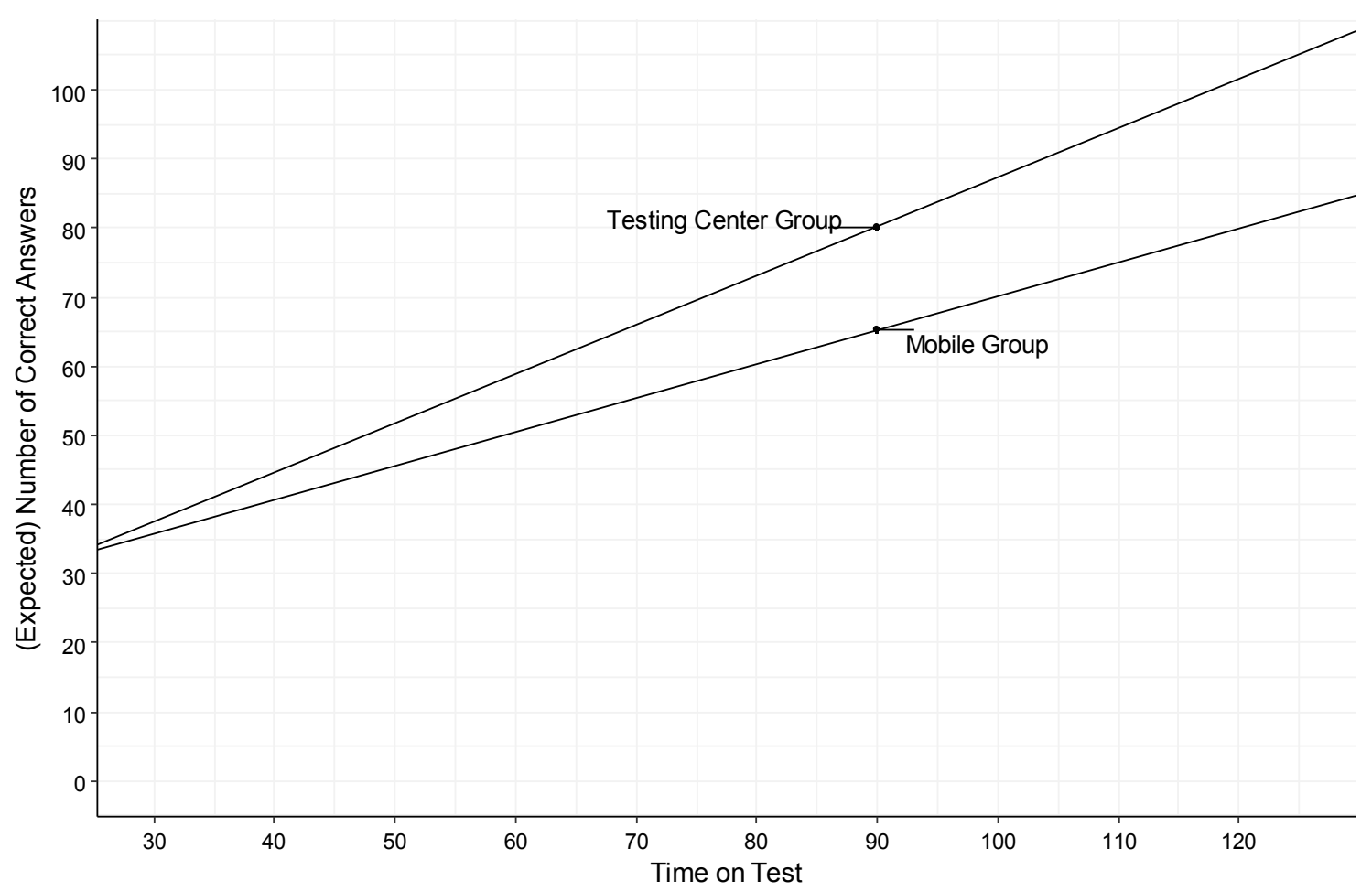

Figure 3. Time on test and its relation to the number of expected correct answers for the two groups. 